\title{
GAMBARAN NILAI TRADISI AUSTRONESIA PADA MASYARAKAT MINANGKABAU DI SALIMPAUNG, KABUPATEN TANAH DATAR, PROVINSI SUMATERA BARAT
}

\author{
Overview of Austronesia Tradition Values in Minangkabau Community \\ in Salimpaung, Tanah Datar District, West Sumatera Province
}

\author{
Nenggih Susilowati \\ Balai Arkeologi Sumatera Utara \\ Jalan Seroja Raya Gg. Arkeologi No 1, Medan Tuntungan, Medan \\ E-mail: nenggih.susilowati@kemdikbud.go.id
}

\begin{abstract}
Speakers of Austronesian languages are known to be partly distributed in several regions of the archipelago, including West Sumatra. Some of the archaeological remains are found in Nagari Situmbuk, and Nagari Supayang, Salimpaung subdistrict, Tanah Datar District. The two nagari become miniature places for the development of culture that illustrates the values of Austronesian traditions. This article aims to determine the characteristics of the development of Austronesian tradisions in traditional buildings and artifacts. It also explores the values of Austronesian traditions in the Minangkabau community in the Salimpaung region. The method used is qualitative with inductive reasoning flow. The data is obtained through survey and excavation activities, with due regard to the form, space and time, including the context of the findings and the natural environment and culture. The existence of artifacts, sites and regions forms a cultural frame that illustrates the existence of Austronesian traditional values in the Minangkabau community. The values include the values of leadership, mutual cooperation, democracy related to religious elements, agricultural livehoods, and betel tradition.
\end{abstract}

Keywords: Austronesian, Minangkabau, traditional values, agriculture, betel

\begin{abstract}
AbSTRAK
Penutur Bahasa Austronesia diketahui sebagian tersebar di beberapa wilayah nusantara, diantaranya Sumatera Barat. Sebagian jejak tinggalan arkeologisnya terdapat di Nagari Situmbuk, dan Nagari Supayang, Kecamatan Salimpaung, Kabupaten Tanah Datar. Kedua nagari tersebut menjadi miniatur tempat berkembangnya budaya yang menggambarkan nilai - nilai tradisi Austronesia. Artikel ini bertujuan untuk mengetahui ciri perkembangan tradisi Austronesia pada bangunan tradisional dan artefaknya. Selain itu juga menggali nilai-nilai tradisi Austronesia pada masyarakat Minangkabau yang berada di wilayah Salimpaung, Kabupaten Tanah Datar, Sumatera Barat. Metode yang digunakan adalah kualitatif dengan alur penalaran induktif. Datadata diperoleh melalui kegiatan survei dan ekskavasi, dengan memperhatikan kerangka bentuk, ruang, dan waktu, meliputi konteks temuan serta lingkungan alam dan budayanya. Keberadaan artefak, situs, dan kawasannya membentuk bingkai budaya yang menggambarkan keberadaan nilai-nilai tradisi Austronesia pada masyarakat Minangkabau. Nilai-nilai itu diantaranya nilai-nilai kepemimpinan, kegotongroyongan, demokrasi yang berkaitan dengan unsur religi, matapencaharian bidang pertanian dan tradisi sirih.
\end{abstract}

Kata kunci: Austronesia, Minangkabau, nilai-nilai tradisi, pertanian, sirih 


\section{PENDAHULUAN}

$\mathrm{P}$ eter Bellwood (2000: 171) menyebutkan bahwa lokasi Proto-Austronesia paling cocok ditempatkan di Taiwan, dengan bukti arkeologis yang menunjukkan adanya permukiman Austronesia paling awal bertarikh antara 4000 dan 3000 SM. Selanjutnya sekelompok bahasa MelayuPolinesia barat memiliki penutur bahasa yang terus berhubungan sepanjang masa sejarah dan tersebar di sebagian besar Vietnam, Sumatera, Borneo (Kalimantan), seluruh Jawa dan Malaysia. Penyebaran bahasa ini terjadi antara 1500-1000 SM (Bellwood, 2000: 177). Pendapat tersebut menggambarkan bahwa bahasa Austronesia diketahui sebagian tersebar di beberapa wilayah Nusantara diantaranya Pulau Sumatera, termasuk Provinsi Sumatera Barat yang dikenal dengan Bahasa Minangkabau. Secara khusus Adelaar (1992 dalam Bellwood, 2000: 177) mengelompokkan bahasa Malayic (Melayu) meliputi bahasa Minangkabau dan Kerinci di Sumatera, dan berbagai dialek Melayu yang digunakan di Sumatera, Jawa bagian barat, kawasan pantai Borneo (Kalimantan), dan Maluku.

Persebaran bahasa terjadi seiring terjadinya proses migrasi sehingga membentuk permukiman yang menyisakan tinggalan arkeologis dengan ciri -ciri tertentu. Sebagian ciri yang menandai persebaran penutur Austronesia di Nusantara sejak masa prasejarah adalah aktivitas pertanian, pemanfaatan sirih, serta pembuatan tembikar dengan teknik tatap landas serta hias motif geometris dengan teknik tera, gores, dan slip (merah), serta pemanfaatan artefak lain. Ciri-ciri tersebut juga berkembang mulai masa prasejarah (budaya neolitik) hingga masa sejarah melalui tradisinya. Sebagian jejak tinggalan arkeologisnya terdapat di
Nagari Situmbuk, dan Nagari Supayang, Kecamatan Salimpaung, Kabupaten Tanah Datar. Kedua nagari tersebut menjadi miniatur tempat berkembangnya nilai nilai tradisi Austronesia, yang berlangsung mulai sebelum hingga sesudah terbentuknya nagari.

Sebelum terbentuknya nagari masyarakat Minangkabau hidup dalam kelompok-kelompok hingga membentuk permukiman mulai dari taratak, dusun, kemudian koto, dan berkembang menjadi nagari (Tim Proyek Sasana Budaya Jakarta, 1986: 10). Nagari adalah suatu unit teritorial yang mempunyai struktur politik dan aparat hukumnya tersendiri, juga sebagai unit permukiman yang paling sempurna yang diakui oleh adat. Kemudian ketika Islam semakin berkembang di daerah Minangkabau terdapat persyaratan untuk menjadi suatu nagari, yaitu suatu permukiman harus memiliki berbagai fasilitas, diantaranya jalan raya, tempat mandi untuk umum, balai adat, masjid, lapangan terbuka untuk hiburan dan olahraga (Kato, 2005: 27). Persyaratan terbentuknya nagari tersebut juga tergambarkan melalui tinggalan arkeologi maupun lingkungan di Nagari Situmbuk dan Nagari Supayang.

Permasalahan yang diajukan adalah: Bagaimana ciri perkembangan tradisi Austronesia pada bangunan tradisional dan artefaknya? Bagaimana nilai-nilai tradisi Austronesia pada masyarakat Minangkabau yang berada di wilayah Salimpaung? Selanjutnya tujuan yang ingin dicapai yaitu mengetahui ciri perkembangan tradisi Austronesia pada bangunan tradisional dan artefaknya. Kemudian menggali nilainilai tradisi Austronesia pada masyarakat Minangkabau yang berada di wilayah Salimpaung, Kabupaten Tanah Datar, Sumatera Barat. 
Metode yang digunakan adalah kualitatif dengan alur penalaran induktif. (dari yang khusus kepada yang umum). Datadata diperoleh melalui kegiatan survei dan ekskavasi, dengan memperhatikan kerangka bentuk, ruang, dan waktu, meliputi konteks temuan serta lingkungan alam danbudayanya. Penelitian yang dilaksanakan tetap mengacu pada tiga tujuan pokok arkeologi meliputi: rekonstruksi sejarah kebudayaan, rekonstruksi cara hidup masyarakat masa lalu, dan penggambaran proses-proses budaya (Tim Tim Pusat Penelitian Arkeologi Nasional, 2000: 8; Soedewo dkk., 2014: 1). Keberadaan tinggalan arkeologis di Nagari Situmbuk dan Nagari Supayang cukup beragam dalam bentuk artefak berbahan batu maupun bangunan tradisional berbahan kayu. Kondisinya ada rusak dan ada yang masih utuh. Beragam tinggalan arkeologis ini dipandang sebagai elemen permukiman di masa lalu yang memiliki keterkaitan satu sama lain

\section{PEMBAHASAN}

\section{Artefak Berciri Tradisi Austronesia di Ngalau Guong Nagari Situmbuk}

Hasil penelitian di ngalau-ngalau yang berada di area perkebunan dan persawahan di kawasan Situmbuk menggambarkan adanya kesinambungan budaya dari masa ke masa berkaitan dengan tradisi Austronesia yang berkembang di sana. Kegiatan yang berkaitan dengan ritual atau religi lama terdapat di Ngalau Tompok Syohiah I berupa menhir dan kubur semu yang menjadi lambang adanya aktivitas berkaitan dengan kepercayaan lama di masa lalu. Sebagai penguat adalah terdapat rock art selain menggambarkan figur manusia, antropomorphik, benda langit seperti matahari, juga terdapat lambang- lambang yang diindikasikan sebagai bentuk penghitungan maupun pertanggalan, pertulisan beraksara Pasca Pallawa, Arab, dan Arab Melayu (Susilowati dan Nasoichah 2018, 59-60; Susilowati dkk. 2017).

Bentuk lain adalah artefak yang terdapat di Ngalau Guong yang menggambarkan adanya aktivitas berkaitan dengan perburuan dan perladangan sederhana. Jejak arkeologis yang didapatkan melalui survei dan ekskavasi berupa fragmen tulang dan gigi fauna, fragmen tembikar (polos dan hias), serta alat batu berupa serpih (diantaranya berbahan obsidian), juga batuan yang merupakan manuport (Susilowati dkk. 2018, 34-38). Diantara gigi fauna yang diidentifikasi geraham belakang dan taring babi (Molar 3 \& Canine - Family Suidae/Sus); geraham belakang, geraham tengah, dan gigi tengah kambing (Molar 3, Molar 2, dan Premolar 4- Subfamilies Caprinae/Capra); geraham kerbau (Molar-Family Bovidae); gigi dan taring landak (Family Hystricidae).

Alat batu/serpih berbahan obsidian berada pada lapisan yang sekonteks dengan temuan tulang, kuku, dan gigi hewan tersebut. Antara artefak dan ekofak tersebut menggambarkan aktivitas yang berkaitan dengan perburuan. Juga terdapat peralatan untuk menumbuk sirih berupa lumpang kecil berdiameter $10 \mathrm{~cm}$ dan penumbuknya. Temuan-temuan itu sekonteks dengan fragmen tembikar polos dan hias yang menandai adanya aktivitas hunian sementara maupun perladangan sederhana. Mengingat tembikar biasanya berfungsi sebagai peralatan memasak atau menyimpan makanan.

Keberadaan fragmen tembikar hias diantaranya memiliki kemiripan dengan tembikar yang ditemukan di situs-situs Austronesia di wilayah lain. Pola-pola 
geometris merupakan pola yang diminati pada masa prasejarah (neolitik dan paleometalik) seperti garis-garis, pola tali, jala, garis horisontal dan vertikal (zigzag), dan pola geometris lain. Indikasi tradisi Austronesia diketahui melalui fragmen tembikar hias dengan pola geometris yang terdapat di Ngalau Guong (lihat Gambar. 1a). Hal lain yang menarik adalah keberadaan batu hampir bulat berdiameter 2, $5 \mathrm{~cm}$ yang dihiasi dengan gambar manusia berwarna hitam dalam posisi kangkang, diperkirakan berfungsi semacam jimat. (Lihat Gambar. 1b). Figur manusia sejenis juga ditemukan pada rock art dalam kaitannya dengan tradisi megalitik di Ngalau Tompok Syohiah I yang posisinya tidak jauh dari Ngalau Guong.
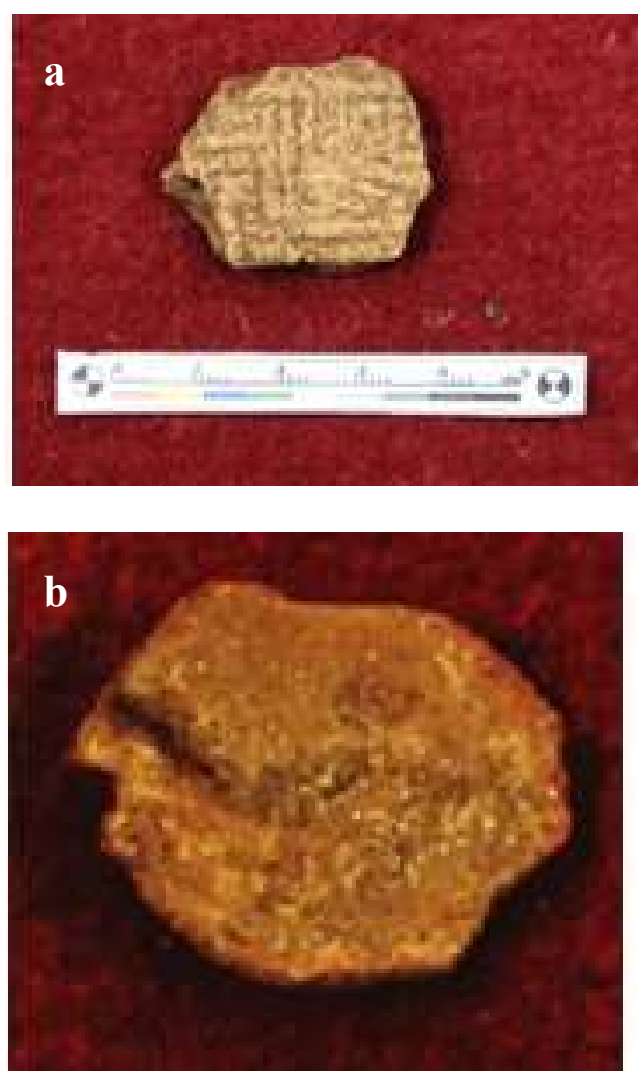

Gambar 1. (a) Tembikar hias tradisi Austronesia; (b) Batu berhias motif manusia kangkang di Ngalau Guong, Nagari Situmbuk. (Sumber: Dok. Nenggih Susilowati, 2019).

\section{Permukiman Lama Bagian dari Tradisi Austronesia}

Permukiman lama di Nagari Situmbuk dan Nagari Supayang berada di antara permukiman baru yang kini semakin padat. Keberadaan permukiman lama ditandai oleh bangunan tradisional yang sebagian dalam kondisi terawat dan sebagian mengalami kerusakan. Bangunan yang ditinggalkan dan mengalami kerusakan umumnya terdapat di Nagari Supayang. Bangunan tradisional itu berbahan kayu berwujud rumah gadang (Rumah besar/rumah Bundo Kanduang) dan rangkiang (lumbung padi). Di bagian halamannya terdapat lasuang (lumpang batu) berjumlah satu buah bahkan lebih, atau palungan batu dan batu berelief (batu bermotif catur dan bermotif bunga). Sebagai penanda berdirinya nagari dan tempat bermusyawarah, berupa bangunan terbuka yang terdiri dari kursi batu (Medan Nan bapaneh).

\section{- Rumah gadang, Rangkiang, dan Lasuang}

Bangunan tradisional Rumah Gadang di Nagari Situmbuk dan Nagari Supayang berupa bangunan panggung berbahan kayu, bertiang kayu, dan beratap seng. Tiangtiang yang digunakan menggunakan batang pohon yang tidak banyak mengalami pengerjaan, sehingga bentuknya kadang agak melengkung. Pada umumnya bangunan adat yang dibangun pada sekitar tahun 1800 -an (awal abad ke- 19) masih dapat bertahan hingga sekarang. Mengingat Kanagarian Situmbuk berdiri pada tanggal 1 Muharam 1237 H (28 September $1821 \mathrm{M})$.

Atap seng merupakan bahan baru yang dahulu menggunakan ijuk. Kemudian bagian ujung atap selalu diberi hiasan yang menjulang ke atas berbahan logam 
(lihat Gambar.2a). Bangunan tradisional di Nagari Situmbuk banyak yang terawat karena ditempati dan digunakan untuk acara pernikahan yang diselenggarakan oleh keluarga, sedangkan di Nagari Supayang banyak yang sudah rusak karena tidak berpenghuni lagi.

Jejak-jejak seninya terlihat dari hiasan ukiran yang berada di bagian dalam dinding atas yang membatasi bilik-bilik rumah gadang di Nagari Situmbuk dan Supayang (lihat Gambar. 2b). Jumlah bilik disesuaikan dengan jumlah jendela yang ada. Hiasan ukiran terdapat pada dinding bagian atas dan pintu bilik atau lemari yang menyambung pada dinding bangunan. Hasni Siat (1999: 15-16) menjelaskan bahwa pada ukiran Minangkabau terdapat dua pola yaitu galuang/relung dan ragam. Galuang/relung yaitu berupa lingkaran yang sambung-bersambung sehingga membentuk relung kearah pusat lingkaran atau ke luar lingkaran. Sedangkan ragam yaitu relung tersebut ditambah unsur lain seperti pola geometris. Pada relung tersebut terdapatlah gagang, daun, bunga, dan buah. Motif lain yang sering terdapat pada rumah gadang diantaranya adalah sulur-suluran seperti siriah gadang (sirih besar) dan kaluak paku (lekukan tanaman pakis).

Unsur lain yang melengkapi rumah adat adalah rangkiang dan lasuang (lumpang) berjumlah satu atau lebih. Rangkiang (lumbung padi) pada umumnya terletak di depan rumah gadang (lihat Gambar 2a). Kini sebagian rangkiang tidak digunakan lagi sebagai tempat menyimpan padi. Bentuk bangunan rangkiang umumnya kecil dan bertiang tinggi dengan pintu di bagian atas dekat atap, sehingga untuk memasukinya diperlukan anak tangga. Rangkiang yang terdapat di Nagari Situmbuk memiliki ornamen yang raya di bagian luarnya, berbeda dengan Rumah gadang hiasannya hanya di bagian dalam. Ukirannya terutama pada bagian atas bangunan yang mendekati bagian atap, bermotif geometris dan sulursuluran.

Di Nagari Situmbuk dan Nagari Supayang sebagian besar lumpang batu sudah tidak digunakan lagi, dahulu berfungsi sebagai alat untuk menumbuk padi menjadi
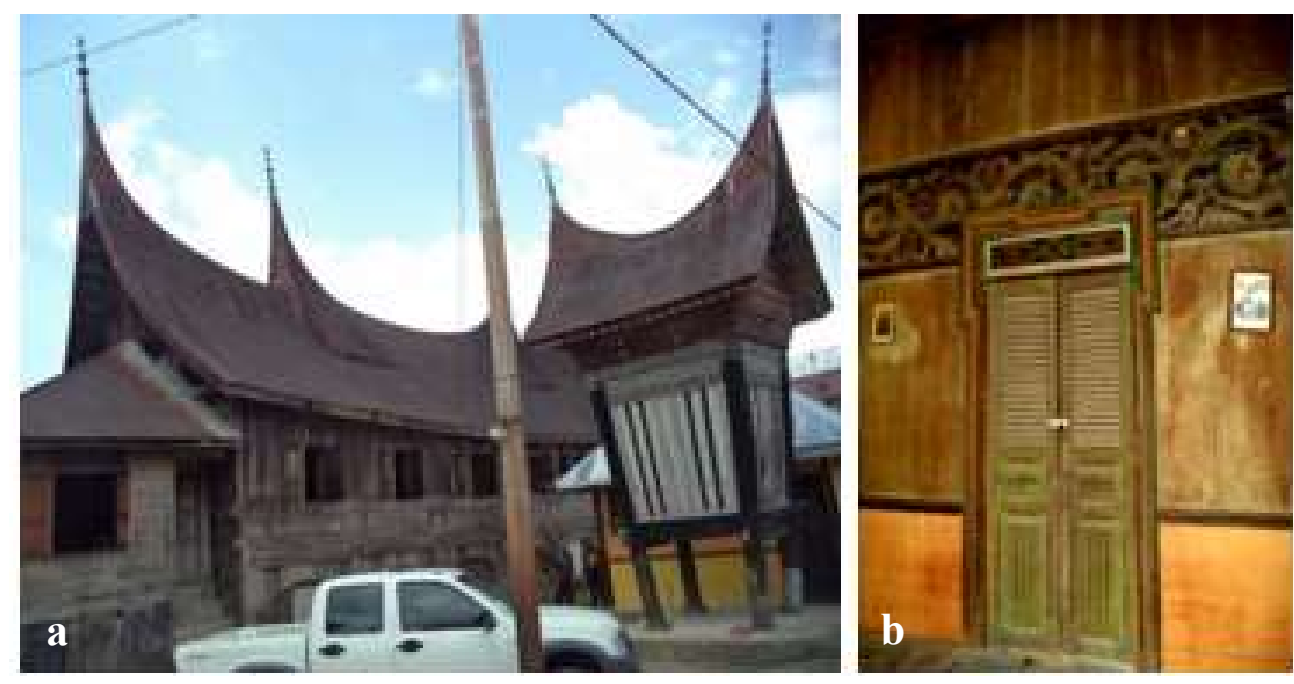

Gambar 2. (a) Rumah Gadang dan rangkiang di Nagari Situmbuk; (b) Ukiran sulur dan bunga pada bagian atas dinding bilik (Sumber: Dok. Balai Arkeologi Sumatera Utara 2017). 
beras. Di Nagari Supayang selain lasuang, juga terdapat palungan batu (tempat minum ternak/kuda) dan batu bergores atau berelief yang disebut sebagai batu catur dan batu bunga. Batu catur merupakan batu yang berpola kotak-kotak dan digunakan dalam permainan seperti catur, sedangkan batu bunga kemungkinan bagian dari permainan anak-anak.

\section{- Medan nan Bapaneh (balai/kursi batu)}

Medan nan bapaneh merupakan susunan kursi batu membentuk denah tertentu (melingkar atau segiempat), di bagian tengah diletakkan meja batu, kadang tidak. Kursi batu dalam istilah arkeologi berupa dua buah batu yang disusun seperti bentuk kursi terdiri dari bagian alas dan sandarannya. Di Sumatera Barat fungsi Medan nan bapaneh sebagai tempat bermusyawarah para penghulu yang dipimpin oleh penghulu pucuk di taratak, koto, dan terutama nagari. Medan nan bapaneh Patir terletak di Jorong

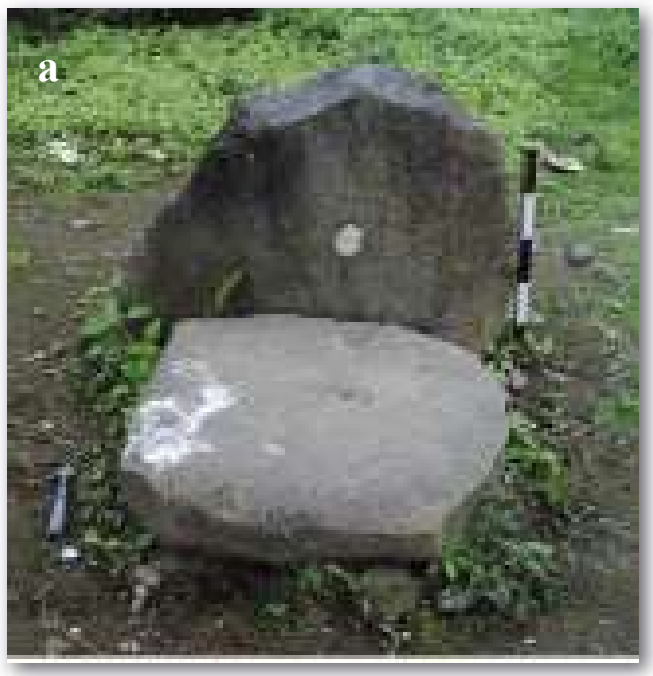

Patir, Nagari Situmbuk, sudah lama tidak difungsikan lagi, terakhir kali digunakan sekitar tahun 1973. Segala aktivitas berkaitan dengan musyawarah telah dipindahkan pada bangunan tradisional yang disebut Balai Kerapatan Adat Nagari, tempat bersidang para penghulu (Nini mamak pemangku adat). Kini kursi-kursi batu ini dalam posisi rebah, hanya satu yang masih tersisa lengkap dengan sandarannya (lihat Gambar.3a).

Kondisi Medan nan bapaneh di Nagari Supayang sebagian telah mengalami perubahan posisi atau tertanam bagian dudukannya akibat pembuatan jalan, seperti pada Batu Tagak di Jorong Picancang dan Batu Sanda Tuanku Cukua Sabalah di Jorong Salo Caniago. Demikian juga Batu Kuciang terletak di Jorong Piliang, Nagari Supayang yang tepat berada di depan rumah penduduk. Lokasi Batu Tagak berada berada di simpang jalan raya Supayang. Kini terdapat 6 kursi batu berdenah segitiga, menggunakan batu alam berbagai ukuran, sebagian berbentuk segiempat pipih. Terdiri dari bagian sandaran dan alasnya (lihat Gambar. 3b). Disebutkan

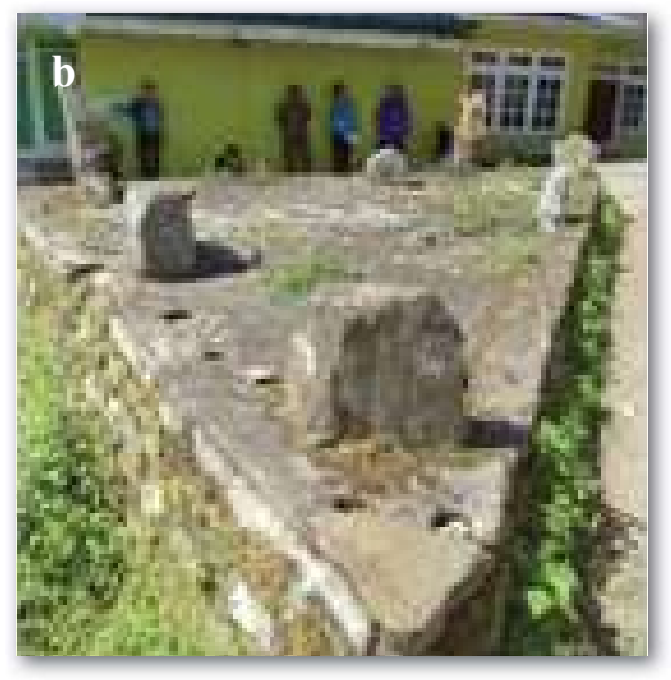

Gambar 3. (a) Salah satu kursi batu di Jorong Patir, Nagari Situmbuk; (b) Batu Tagak di Nagari Supayang (Sumber: Dok. Balai Arkeologi Sumatera Utara 2017). 
bahwa kursi batu tersebut milik masyarakat Suku Caniago di Nagari Supayang. Aswar (1999: 38-39) menjelaskan bahwa suku dalam kekerabatan Minangkabau menyerupai suatu kaum matrilineal, yang dipimpin oleh penghulu suku.

\section{Gambaran Nilai-Nilai Budaya dan Tradisi Austronesia pada Masyarakat Salimpaung}

Tradisi Austronesia yang terdapat di Nagari Situmbuk diantaranya dicirikan dengan aktivitas pertanian yang diawali dengan perladangan sederhana yang disertai perburuan seperti yang terdapat di Ngalau Guong. Pembuatan tembikar dan pemanfaatannya menjadi ciri bagi kehidupan yang mulai menetap, diawali dengan hunian sementara pada ceruk hingga kemudian membentuk permukiman. Ciri tradisi Austronesia muncul di sana melalui fragmen tembikar hias dengan motif geometris serta teknik tatap landas yang digunakan. Tembikar hias dengan teknik tera maupun gores, juga semakin menguatkan adanya pengaruh budaya tersebut.

Perkembangan budaya Austronesia dengan ciri-ciri khasnya tidak hanya berkaitan dengan perkembangan pada masa prasejarah, terutama pada masa Neolitik, melainkan juga pada masa-masa sesudahnya seiring dengan perkembangan budaya lokal. Mengutip pendapat Truman Simanjuntak (2015: 26-28) bahwa situs-situs Neolitik di Nusantara dikaitkan dengan migrasi penutur Austronesia, periode paling tua Austronesia prasejarah sekitar 4000 tahun hingga sekitar 2000 BP. Kemudian Austronesia Protosejarah berkembang di sekitar 2000 BP-abad IV/V Masehi. Kemudian berlanjut hingga masa-masa sejarah yang dimulai pada masa-masa berkembangnya kerajaan di
Nusantara yang diawali dari masa Hindu Buddha hingga masa kemudian.

Kronologi tradisi Austronesia di Nagari Situmbuk diperkirakan awalnya dijumpai di Ngalau Guong dengan aktivitas perladangan sederhana yang masih diwarnai dengan perburuan, yang terjadi pada masa sebelum atau setara dengan perkembangan aksara Pasca Pallawa sebagai rock art di Ngalau Tompok Syohiah 1, Situmbuk pada sekitar 1500-an/abad ke-16 M. Selain itu temuan tembikar dengan hias manusia berwarna hitam di Ngalau Guong menguatkan kronologi itu mengingat motifnya mirip dengan gambaran manusia pada rock art tersebut.

Ciri lain yang menggambarkan adanya tradisi Austronesia adalah tradisi menyirih yang pernah ada di wilayah Nagari Situmbuk. Kebiasaan menyirih dapat dikatakan sudah mulai ditinggalkan, namun pemanfaatan sirih dan pelengkapnya seperti kapur sirih, pinang, gambir tetap dimunculkan dalam kegiatan adat maupun sesaji yang diletakkan di Ngalau Tompok Syohiah I. Artefak peralatan menyirih berupa lumpang kecil dan alat pemukulnya dari batu yang ditemukan di Ngalau Guong menguatkan adanya tradisi itu di masa lalu. Simbolsimbol berwujud motif hias sulur-suluran pada rumah gadang maupun rangkiang, diantaranya menggambarkan tanaman sirih juga merupakan keterpengaruhan budaya Austronesia.

Aktivitas pertanian yang intens selanjutnya membentuk nilai kearifan lokal bergotong-royong dalam memelihara pengairan, membentuk kelompok petani serta memelihara dan membagi pengairan dengan baik. Aktivitas tersebut didukung oleh pemilihan lahan yang potensial sebagai areal pertanian yang dekat 


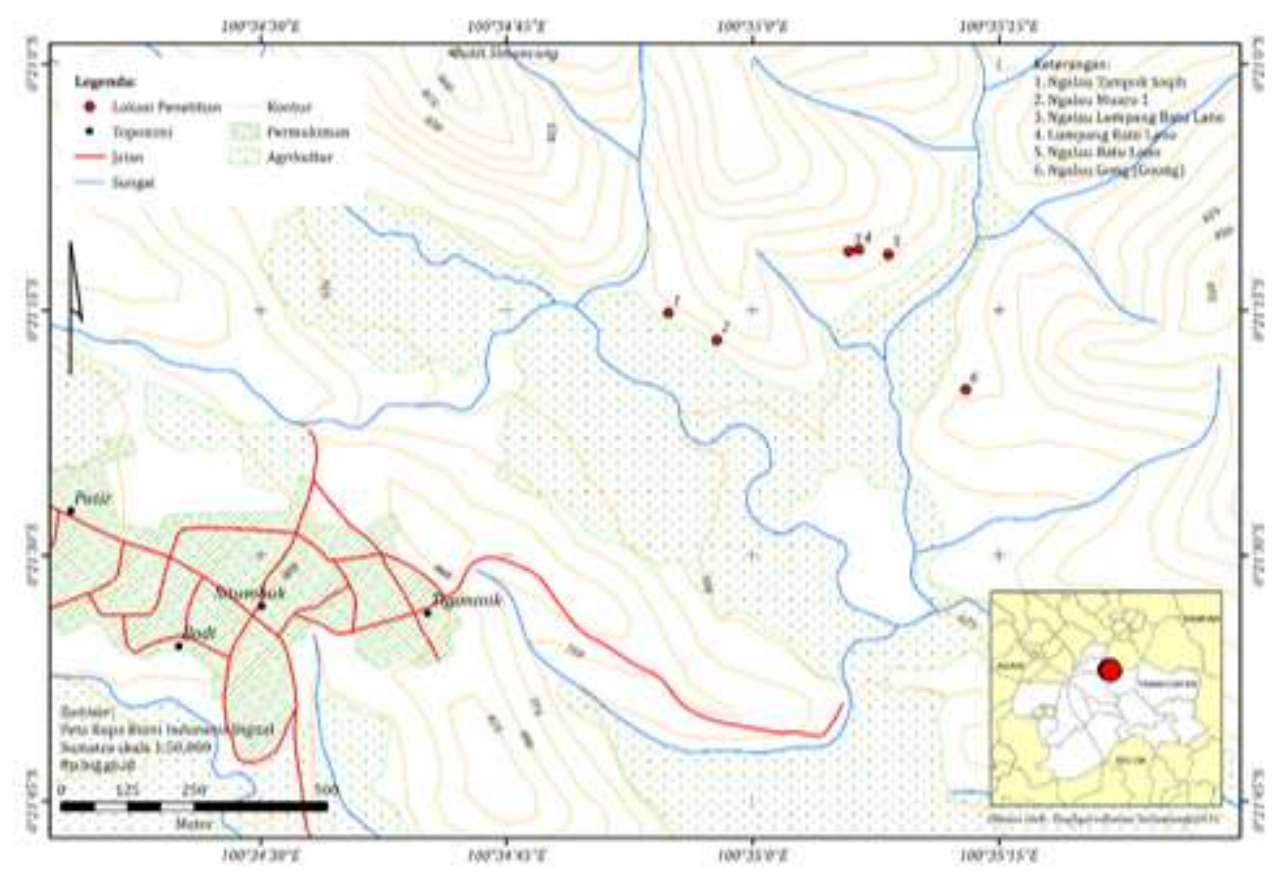

Gambar 4. Peta situasi Nagari Situmbuk (Sumber: Dok. Balai Arkeologi Sumatera Utara 2018)

dengan mata air dan sungai. Pemilihan lahan permukiman merupakan kearifan lokal dalam memperhatikan faktor-faktor kebencanaan yang mungkin terjadi di wilayah Nagari Situmbuk. Area yang subur sebagai lahan pertanian terutama di bagian lembah sekaligus sebagai area yang rawan banjir, yang diketahui melalui kondisi terjadinya banjir pada tahun 1979 dan 2009. Bencana yang terjadi tidak merusak bagian permukimannya yang berada pada bagian dengan kontur tanah yang tinggi dibandingkan area pertaniannya (lihat Gambar. 4). Pembagian ruang telah dilakukan oleh masyarakat Situmbuk dengan memperhatikan faktor-faktor alam dan kebencanaan.

Nilai tradisi yang lain adalah tradisi bermusyawarah masyarakatnya, diketahui melalui keberadaan medan nan bapaneh, hingga Balai Kerapatan Adat yang sekaligus kini menjadi Kantor Wali Nagari. Medan nan bapaneh Patir, Batu Tagak, dan Batu Sanda Tuanku Cukua Sabalah menjadi saksi kegiatan musyawarah yang dilaksanakan oleh para penghulu di masa lalu. Kursi batu tertentu biasanya diduduki oleh penghulu pucuk yang memimpin musyawarah adat. Hal ini menggambarkan nilai-nilai kepemimpinan di masa lalu yang diwarisi hingga kini, dengan tetap memperhatikan kondisi kini yang wilayahnya juga dipimpin oleh Wali Nagari.

Di dalam tambo juga disebutkan ketika pemerintahan Datuk Suri Dirajo, didirikan Balai nan Saruang dengan beratap langit, berdinding angin, dan berlantai batu. Balai itulah yang menjadi tempat bermufakat pembesar kerajaan (Nopriyasman, 2008: 123). Pemilihan pada area yang lapang dan terbuka dimaksudkan agar keputusankeputusan yang diambil oleh para penghulu itu dapat didengar langsung oleh masyarakat. Musyawarah untuk mufakat, serta keterbukaan dalam mengeluarkan pendapat menjadi ciri demokrasi masyarakat di sana. Selanjutnya medan nan bapaneh sebagai tempat bermusyawarah juga melengkapi dan 
menandai kesatuan hunian dalam kelompok suku maupun nagari pada suatu permukiman.

\section{SIMPULAN}

Jejak-jejak budaya Austronesia diketahui melalui tinggalan arkeologis yang mendukung kehidupan manusia sebelum dan ketika pembentukan nagari. Berawal dari kehidupan manusia ketika masih menghuni ceruk dan gua seperti Ngalau Guong dengan aktivitas perburuan dan perladangan sederhana. Kemudian ketika membentuk nagari, tradisi Austronesia terlihat melalui aktivitas pertanian, dan elemen permukimannya seperti rumah panggung (rumah gadang), lumbung padi (rangkiang) dan lumpang batu (lasuang), serta kehidupan bermasyarakat dengan kepemimpinan penghulu yang ditandai dengan medan nan bapanehnya.

Pemilihan bentang lahan yang berbeda untuk permukiman dan pertanian, dengan menempatka permukiman pada kontur yang lebih tinggi dibandingkan lahan pertanian dan perkebunan. Religi berkembang mulai dari kepercayaan lama hingga Islam, dimulai dari aktivitas hunian ceruk hingga membentuk permukiman dalam nagari. Tradisi menyirih yang menjadi ciri persebaran budaya Austronesia juga muncul di wilayah Salimpaung. Secara umum nilainilai kearifan lokal yang menggambarkan ciri tradisi Austronesia meliputi; kepemimpinan, demokrasi, kegotong-royongan, serta kearifan lokal dalam pemilihan lahan bagi permukiman.

\section{DAFTAR PUSTAKA}

Aswar, Sativa Sutan. (1999). Antekusuma Suji Dalam Adat MinangkabauAntakesuma Embroidery in the
Minangkabau Adat. Jakarta: Djambatan.

Bellwood,Peter.(2000).Prasejarah Kepulauan Indo- Malaysia. Edisi Revisi. Jakarta: PT. Gramedia Pustaka Utama.

Kato, Tsuyoshi. (2005). Adat Minangkabau dan Merantau dalam Perspektif Sejarah. Jakarta: Balai Pustaka

Nopriyasman. (2008). Sri Maharaja Diraja: Mitos dan Realitas dalam Sejarah Pembesar di Minangkabau. Titik Balik Historiografi di Indonesia. Jakarta: Wedatama Widya Sastra \& Departemen Sejarah FIB UI.

Siat, Hasni, Rusmita, Mutia, Riza. (1999). Ukiran Tradisional Minangkabau. Sumatera Barat: Bagian Proyek Pembinaan Permuseuman

Soedewo, Ery, Koestoro, Lucas Partanda, Wiradnyana, Ketut, dan Oetomo, Repelita Wahyu. (2014). Balai Arkeologi Medan: Profil Lembaga dalam Dinamika Hasil Penelitian Arkeologi di Sumatera Bagian Utara. Medan: Balai Arkeologi Medan.

Simanjuntak, Truman. (2015). Progres Penelitian Austroneisa di Nusantara. AMERTA, Jurnal Penelitian dan Pengembangan Arkeologi 33 (1): 25 44.

Susilowati, Nenggih, dan Nasoichah, Churmatin. (2018). Identifikasi dan Pemaknaan Simbol-Simbol pada Gambar Cadas di Ngalau Tompok Syohiah I, Nagari Situmbuk, Sumatera Barat. Sangkhakala 21 (1): 56-79.

DOI: https://doi.org/10.24832/bas.v21i1.324

Susilowati, Nenggih, Setiawan, Taufiqurrahman, Nasoichah, Churmatin, dan Wiradnyana, Ketut. (2017). Penelitian Arkeologi Prasejarah di Kabupaten Tanah Datar, Provinsi Sumatera Barat. Medan: Balai Arkeologi Medan. 
Susilowati, Nenggih, Setiawan, Tim Pusat Penelitian Arkeologi Nasional. Taufiqurrahman, Simatupang, Defri Elias, Wiradnyana, Ketut, Lismawati, dan Hidayat, Teguh. (2018). Ekskavasi di Ngalau Tompok Syohiah I, Nagari Situmbuk, Kecamatan Salimpaung dan Survei Situs Arkeologi di Sekitarnya). Medan: Balai Arkeologi Medan. (2000). Metode Penelitian Arkeologi. Jakarta.

\section{HASIL DISKUSI}

> Tidak ada pertanyaan

Tim Proyek Sasana Budaya Jakarta, Depdikbud. (1986). Arsitektur Tradisional Minangkabau Rumah Gadang. Jakarta: Pustaka Wisata Budaya 